\title{
Catalase Overexpression Drives an Aggressive Phenotype in Glioblastoma
}

\author{
Susanne Flor ${ }^{1,+}{ }^{-}$, Claudia R. Oliva ${ }^{1,+}$, Md Yousuf Ali ${ }^{2}$, Kristen L. Coleman ${ }^{3}$, Jeremy D. Greenlee ${ }^{4}$, \\ Karra A. Jones ${ }^{5}(\mathbb{D})$, Varun Monga ${ }^{6}$ id and Corinne E. Griguer ${ }^{1, *}$
}

1 Free Radical \& Radiation Biology Program, Department of Radiation Oncology, University of Iowa, Iowa, IA 52242, USA; susanne-flor@uiowa.edu (S.F.); claudia-oliva@uiowa.edu (C.R.O.)

2 Interdisciplinary Graduate Program in Human Toxicology, Department of Radiation Oncology, University of Iowa, Iowa, IA 52242, USA; ali-mdyousuf@uiowa.edu

3 Holden Comprehensive Cancer Center, University of Iowa, Iowa, IA 52242, USA; kristen-coleman@uiowa.edu

4 Department of Neurosurgery, University of Iowa, Iowa, IA 52242, USA; jeremy-greenlee@uiowa.edu

5 Department of Pathology, University of Iowa, Iowa, IA 52242, USA; karra-jones@uiowa.edu

6 Department of Internal Medicine, University of Iowa, Iowa, IA 52242, USA; varun-monga@uiowa.edu

* Correspondence: corinne-griguer@uiowa.edu

+ These authors contributed equally to this work.

check for

updates

Citation: Flor, S.; Oliva, C.R.;

Ali, M.Y.; Coleman, K.L.;

Greenlee, J.D.; Jones, K.A.; Monga, V.;

Griguer, C.E. Catalase Overexpression

Drives an Aggressive Phenotype in

Glioblastoma. Antioxidants 2021, 10,

1988. https://doi.org/10.3390/

antiox10121988

Academic Editors: Edward E. Schmidt, Hozumi Motohashi and Anna Kipp

Received: 13 November 2021

Accepted: 8 December 2021

Published: 14 December 2021

Publisher's Note: MDPI stays neutral with regard to jurisdictional claims in published maps and institutional affiliations.

Copyright: (C) 2021 by the authors. Licensee MDPI, Basel, Switzerland. This article is an open access article distributed under the terms and conditions of the Creative Commons Attribution (CC BY) license (https:/ / creativecommons.org/licenses/by/ $4.0 /)$.

\begin{abstract}
Glioblastoma remains the deadliest form of brain cancer, largely because these tumors become resistant to standard of care treatment with radiation and chemotherapy. Intracellular production of reactive oxygen species (ROS) is necessary for chemo- and radiotherapy-induced cytotoxicity. Here, we assessed whether antioxidant catalase (CAT) affects glioma cell sensitivity to temozolomide and radiation. Using The Cancer Genome Atlas database, we found that CAT mRNA expression is upregulated in glioma tumor tissue compared with non-tumor tissue, and the level of expression negatively correlates with the overall survival of patients with high-grade glioma. In U251 glioma cells, CAT overexpression substantially decreased the basal level of hydrogen peroxide, enhanced anchorage-independent cell growth, and facilitated resistance to the chemotherapeutic drug temozolomide and ionizing radiation. Importantly, pharmacological inhibition of CAT activity reduced the proliferation of glioma cells isolated from patient biopsy samples. Moreover, U251 cells overexpressing CAT formed neurospheres in neurobasal medium, whereas control cells did not, suggesting that the radio- and chemoresistance conferred by CAT may be due in part to the enrichment of glioma stem cell populations. Finally, CAT overexpression significantly decreased survival in an orthotopic mouse model of glioma. These results demonstrate that CAT regulates chemo- and radioresistance in human glioma.
\end{abstract}

Keywords: catalase; glioblastoma multiforme; reactive oxygen species (ROS); hydrogen peroxide; radiation; temozolomide

\section{Introduction}

Glioblastoma (GBM) is the most aggressive form of brain cancer, with a mean survival of only 14 months [1], even with the current standard of care treatment, which includes temozolomide (TMZ) combined with radiotherapy [2,3]. Although there is a significant initial benefit, treatment eventually becomes ineffective due to the development of tumor cell resistance. Indeed, resistance to radio-chemotherapy presents the most challenging barrier in the successful treatment of cancer and is one of the main phenomena underlying the failure to achieve a sustainable clinical benefit for patients with GBM [4,5].

Many factors have been associated with GBM resistance to radiation and chemotherapy, including tumor hypoxia, efficient and redundant DNA repair capacities [6], glioma stem cells (GSCs) [7], and increased expression of antioxidant enzymes that reduce the accumulation of reactive oxygen species (ROS) [8,9]. ROS comprises free radicals (superoxide, hydroxyl radical, singlet oxygen) and non-radical species (e.g., hydrogen 
peroxide $\left[\mathrm{H}_{2} \mathrm{O}_{2}\right]$ ) that activate signaling pathways necessary for cell growth, proliferation, and differentiation $[10,11]$. However, excess cellular levels of ROS cause damage to important macromolecules, such as DNA, proteins, and lipids [12], which can lead to the activation of cell death signaling pathways [13,14]. Intracellular ROS levels are controlled by a complex network of antioxidant enzymes (e.g., superoxide dismutase and glutathione peroxidase) [15].

CAT is a key enzyme in the metabolism of $\mathrm{H}_{2} \mathrm{O}_{2}$. The molecular mechanisms regulating the expression of catalase (CAT) are not completely understood. Altered expression levels of CAT have been reported in tumor tissues. Specifically, the downregulation of CAT expression has been shown in pancreatic cancer cells and mouse skin tumors [16,17], but upregulation of CAT expression has been reported in melanoma [18], colon cancer [19], gastric adenocarcinoma [20], and GBM [21] cells. Importantly, altered CAT expression has been correlated with resistance to therapy in GBM [22,23], pancreatic cancer [9], and breast cancer cells [24]. In our previous studies, we demonstrated that glioma cell resistance to TMZ-induced oxidative stress is mediated by a reduction in the levels of mitochondrial ROS and enhanced antioxidant production and is associated with increased CAT activity $[21,25,26]$.

Although studies by us and others have indicated an inverse correlation between the level of CAT expression or activity and resistance to therapy in different cancer cells, other studies have shown divergent results. In particular, controversy remains as to whether CAT is up- or downregulated in gliomas [22,25-28]. Thus, it is important to understand the precise roles of CAT in GBM biology and resistance to therapy. In this study, we investigated the association between CAT expression in GBM tumors and patient survival, as well as the cellular and molecular mechanisms by which CAT influences therapeutic resistance in GBM.

\section{Materials and Methods}

\subsection{Gene Expression Analyses}

For comparisons between high-grade glioma and normal brain samples, CAT read counts of non-tumor (28 samples), mixed glioma (11 samples), oligodendroglioma (67 samples), astrocytoma (147 samples), and GBM (219 samples) were obtained from TCGA. Evaluation of TCGA glioma patient gene expression data and survival analysis were performed with the TCGA Rembrandt dataset. For Kaplan-Meier survival analysis, median gene expression was selected as the cutoff to split high and low expresser populations. The TCGA database can be downloaded from the GlioVis data portal (http:/ /gliovis.bioinfo.cnio.es/, date accessed 8 September 2021).

\subsection{Cell Culture and Electroporation}

Glioma cells were cultured as we previously described [21,29,30]. Cells were electroporated using a Gene Pulser Xcell Electroporation System (BioRad, Hercules, CA, USA) under the following conditions: square wave pulse, $25 \mathrm{msec}$, and 140V. U251 cells were electroporated with CMV6 plasmids containing Myc-DDK-epitope-tagged human CAT or the pCMV6-Entry mammalian vector with C-terminal Myc-DDK Tag as the control (Catalog \# RC210763 and PS100001, respectively; OriGene Technologies, Rockville, MD, USA). To generate cell lines stably overexpressing CAT, cells were selected with G418 $(800 \mu \mathrm{g} / \mathrm{mL})$ for 15 days. The stable lines isolated were characterized for the level of CAT by Western blot analysis and enzymatic activity.

\subsection{CAT Activity}

CAT activity was determined as previously described [28]. Briefly, cells were plated in 100-mm tissue culture plates and grown to $70-75 \%$ confluence. Cells were washed twice in phosphate buffered saline (PBS) and then collected and lysed in $50 \mathrm{mM}$ potassium phosphate buffer $(\mathrm{PB}) \mathrm{pH} 7.0$ via sonication. For each sample, $100 \mu \mathrm{g}$ of cell extract was added to $30 \mathrm{mM} \mathrm{H}_{2} \mathrm{O}_{2}$ in $50 \mathrm{mM} \mathrm{PB} . \mathrm{H}_{2} \mathrm{O}_{2}$ consumption was measured at $240 \mathrm{~nm}$ for $180 \mathrm{~s}$ 
(recorded at 15-s intervals) using a Beckman DU 800 UV spectrophotometer (Beckman Coulter, Brea, CA, USA) at $37^{\circ} \mathrm{C}$. For pharmacological inhibition of CAT, cells were treated with 3-AT or vehicle (DMSO) for $24 \mathrm{~h}$. Cells were then washed in PBS and used for subsequent experiments.

\subsection{Acquisition of Tissue Specimens and Tumor Dissociation}

The protocol for this study was approved by the Institutional Review Board for Human Use at the University of Iowa (IRB 201103721). Patients with high-grade gliomas were identified by the University of Iowa, Tissue Procurement Core for inclusion in the Glioma Library Project. All patients provided written informed consent for the surgical procedures and gave permission for the use of resected tissue specimens, and all samples were de-identified to maintain confidentiality. Tumor tissues were dissociated into singlecell suspensions using a Brain Tumor Dissociation Kit (Miltenyi Biotec Inc., Auburn, CA, USA) according to the manufacturer's protocol. Single-cell suspensions were cultured in a neurobasal medium as we previously described [21,31]. Cell stocks were stored in liquid nitrogen until use.

\subsection{Measurement of Intracellular ROS}

The generation of $\mathrm{H}_{2} \mathrm{O}_{2}$ was measured using $10 \mu \mathrm{M}$ Amplex ${ }^{\mathrm{TM}}$ Red (ThermoFisher Scientific, Waltham, MA, USA, Cat. \# A12222) in the presence of 38 units $/ \mathrm{mL}$ superoxide dismutase (SOD; Sigma, St. Louis, MO, USA, CAT. \# S9697) and 5 units $/ \mathrm{mL}$ horseradish peroxidase (HRP; Sigma, St. Louis, MO, USA, Cat. \# P8375). The fluorescent signal generated by the oxidation of the probe was measured using a FluoroMax-3 spectrofluorometer

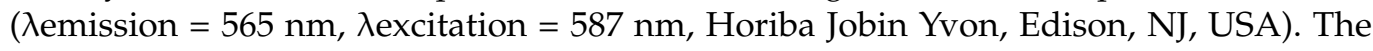
fluorescence values of each experiment were converted to $\mathrm{H}_{2} \mathrm{O}_{2}$ concentration using a standard curve and expressed as pmoles $/ \mathrm{min} / 10^{5}$ cells.

\subsection{Cell Proliferation and Anchorage-Independent Clonogenic Assays}

For cell proliferation, cells were seeded into 6 -well plates $\left(2 \times 10^{4}\right.$ cells $/$ well $)$. Cell number was assayed every $24 \mathrm{~h}$ for 5 days using a TC20 automated cell counter (BioRad, Hercules, CA, USA). For crystal violet cell proliferation assays [32], cells were fixed with ice-cold 3.7\% paraformaldehyde, washed twice with PBS, and stored at $-80^{\circ} \mathrm{C}$ overnight. Cells were then stained with $0.05 \% \mathrm{CV}$ solution and air-dried. The dye was solubilized with $10 \%$ acetic acid, and absorbance was measured at $590 \mathrm{~nm}$. Anchorage-independent clonogenic assays were performed as we previously described [21,33].

\subsection{Xenograft GBM Tumors}

All surgical and experimental procedures and animal care practices were performed in compliance with the policies approved by the Institutional Animal Care and Use Committee of the University of Iowa. Establishment of intracranial tumors was performed as we previously described [21,34]. Any animal exhibiting signs of neurological deterioration was killed and the brain removed for examination. Paraffin-embedded tumor tissues were serially sectioned $(5 \mu \mathrm{m})$, and sections were counterstained with hematoxylin and eosin (H\&E, Abcam, Waltham, MA, USA, Cat. \# ab245880), as we previously described [21].

\subsection{Clonogenic Survival Assays}

Clonogenic survival assays were performed as previously described [35]. Briefly, cells were plated and allowed to attach for $24 \mathrm{~h}$, then treated with 50-250 $\mu \mathrm{M} \mathrm{TMZ}$ or $0.5 \%$ DMSO (vehicle control) for $48 \mathrm{~h}$ followed by irradiation (2-8 Gy) at a dose rate of $0.65 \mathrm{~Gy} / \mathrm{min}^{-1}$ using a $6000 \mathrm{Ci}^{137} \mathrm{C}$ s source. Cells were trypsinized immediately after treatment, counted, and seeded into 6-well plates at varying densities. The dishes were maintained in an incubator at $37^{\circ} \mathrm{C}$ for 10 days to allow colony formation. The colonies were then fixed with $70 \%$ ethanol, stained with Coomassie blue, and counted (colonies 
containing $>50$ cells were scored). Plating efficiency was determined by the following formula: (number of colonies formed/number of cells inoculated) $\times 100$.

\subsection{Cell Cycle Analysis}

Cell cycle analysis was performed as we previously described [34]. Briefly, cells were treated with DMSO (control) or $300 \mu \mathrm{M}$ TMZ for $48 \mathrm{~h}$, then washed with PBS, trypsinized, and resuspended in PBS with $0.1 \%$ TritonX-100. PI and ribonuclease A were added at a final concentration of $10 \mu \mathrm{g} / \mathrm{mL}$. Cells were analyzed by flow cytometry with a BD FACScalibur for DNA content, and the percentage of cells in the G1, S, and G2/M phases was established using ModFit LT (Verity Software House, Topsham, ME, USA).

\subsection{Determination of Apoptosis}

The apoptotic response after treatment with $250 \mu \mathrm{M}$ TMZ or $10 \mu \mathrm{M}$ staurosporine (positive control) was measured by flow cytometry as we described previously [29,30]. Treated and untreated cells were harvested, washed once with PBS, and stained with an Annexin V-PE Apoptosis Detection Kit (BD Pharmigen, San Diego, CA, USA) according to the manufacturer's instructions. Samples were analyzed by flow cytometry using a BD LSR II flow cytometer using $\lambda$ Ex. 492-495 nm, $\lambda$ Em. 517-527 nm. For each sample, 10,000 cells were analyzed, and the number of apoptotic cells was calculated with FlowJo Software Version 10 (FlowJo, LLC, Ashland, OR, USA).

\subsection{In Vitro Limiting Dilution Assay}

In vitro dilution assays were performed as we previously described [21,34,36]. Briefly, cells were plated at 1, 2, 5, 10, 25, 50, 100, and 200 cells per well in 96-well plates in the presence or absence of 3-AT (25 mM). Ten days after plating, the number of neurospheres in each well and the percentage of positive wells were quantified by manual counting. Extreme limiting dilution assay analyses were performed on the data as we previously described [21].

\subsection{Statistics}

Data were evaluated using GraphPad. Differences among the groups were tested using either unpaired two-tailed $t$-test or one- or two-way analysis of variance (ANOVA) followed by Tukey's multiple comparison test, and probability $(p)$ values were reported, with $p<0.05$ indicating statistical significance. Experiments were performed in duplicate or triplicate and repeated twice or more to verify results. Data are expressed as the mean \pm standard deviation (SD) and significance indicated as follows: $p<0.05\left({ }^{*}\right), p<0.01\left({ }^{* *}\right), p<0.001\left({ }^{* *}\right)$, and $p<0.0001\left(^{* * *}\right)$, respectively.

\section{Results}

\subsection{Overexpression of CAT in Malignant Brain Tumors}

We previously reported that CAT activity is elevated in TMZ-resistant glioma cells [21]. To investigate if CAT expression is clinically relevant in gliomas, we interrogated The Cancer Genome Atlas (TCGA) data accessed via GlioVis [37]. We compared CAT mRNA levels in glioma tumor tissue to levels in control brain tissues in datasets from Rembrandt cohorts comprising results from 537 samples. Compared with the expression in non-tumor tissue, CAT mRNA expression was significantly upregulated in astrocytoma, oligodendroglioma, mixed glioma, and GBM samples (Figure 1A, Supplementary Table S1). Analysis of CAT mRNA in glioma samples of different grades showed that the level of CAT mRNA expression in the tumor correlated inversely with overall survival (OS) in patients (high median CAT expression: $\mathrm{OS}=18.0$ months; low median CAT expression: $O S=23.4$ months; $p=0.0107$ by log-rank test) (Figure 1B). Together, these results confirm that human glioma tumors express high levels of CAT, and higher tumor expression of CAT is associated with poor prognosis. 
A

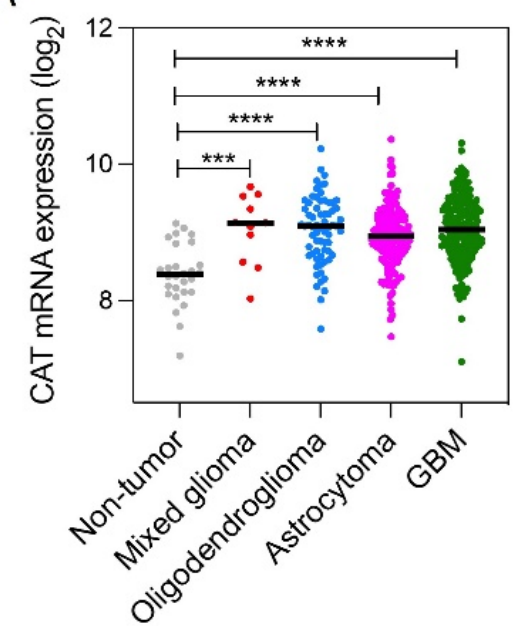

B

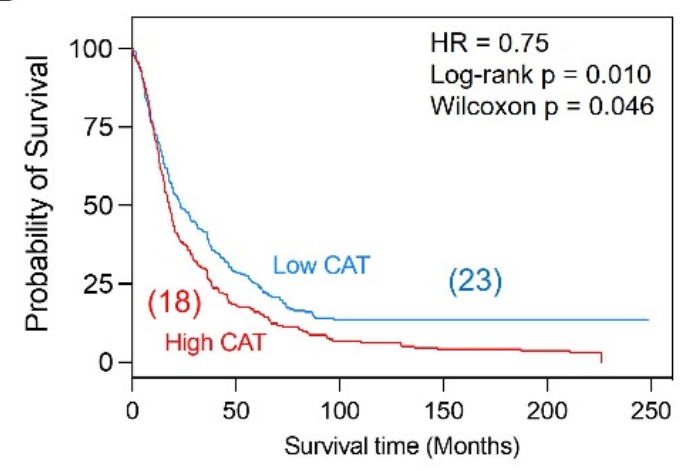

Figure 1. Expression of CAT mRNA in human glioma. (A) Expression of CAT mRNA in glioma tissue and non-tumor brain tissue samples from the Rembrandt dataset. Median values are represented as lines in the scatter plot. ${ }^{* * *} p<0.001{ }^{* * * *} p<0.0001$ by ANOVA. (B) Kaplan-Meier survival curves of overall survival in patients with glioma stratified by CAT mRNA expression levels in tumors (low CAT, $n=208$; high CAT, $n=189$ ). Numbers between brackets indicate median survival time. CAT, catalase.

\subsection{Stable Overexpression of CAT Results in Decreased Levels of Intracellular $\mathrm{H}_{2} \mathrm{O}_{2}$}

To evaluate the effect of CAT overexpression on glioma phenotype, we stably transfected U251 glioma cells with a vector encoding CAT cDNA. U251 cells stably transfected with an empty vector were used as the control. CAT protein expression was verified by Western blot analyses (Figure 2A) and assays for enzymatic activity $\left(\mathrm{H}_{2} \mathrm{O}_{2}\right.$ consumption) (Figure 2B). CAT expression in parental and vector-transfected cells is often weak or undetectable by western blot under the tested conditions, confirming the low abundance of CAT in U251 cells. We selected U251 clone 3, which exhibited CAT activity 15 times higher than that in control cells, for further analysis. Treatment with an irreversible inhibitor of CAT [38], 3-amino-1,2,4-triazole (3-AT; $25 \mathrm{mM}$ for $24 \mathrm{~h}$ ), completely abrogated CAT activity in the CAT-overexpressing cells, demonstrating that the difference in CAT activity between the two cell types is due to CAT overexpression (Figure 2C). To assess whether CAT overexpression contributes to ROS scavenging, cellular levels of $\mathrm{H}_{2} \mathrm{O}_{2}$ were measured by monitoring the oxidation of Amplex Red using a spectrofluorometer (FluoroMax-3; Horiba Jobin Yvon, Edison, NJ, USA). As shown in Figure 2B, overexpression of CAT induces a 10-fold decrease in $\mathrm{H}_{2} \mathrm{O}_{2}$ production compared with $\mathrm{H}_{2} \mathrm{O}_{2}$ formation by vector-transfected cells ( $1.61 \pm 0.07$ and $15.97 \pm 0.65$ pmoles $/ \mathrm{min} / 10^{5}$ cells, respectively). Treatment with 3-AT $(25 \mathrm{mM}, 24 \mathrm{~h})$ increases $\mathrm{H}_{2} \mathrm{O}_{2}$ production in CAT cells (12.63 \pm 0.58 pmoles $/ \mathrm{min} / 10^{5}$ cells), indicating that $\mathrm{H}_{2} \mathrm{O}_{2}$ depletion is due to CAT overexpression (Figure 2D).

\subsection{CAT Overexpression Promotes Cell Proliferation}

Since ROS activates signaling pathways that contribute to the regulation of cell proliferation [25], we investigated whether CAT overexpression in glioma cells is associated with a change in cell proliferation. When adherent cell growth was assessed, the doubling time did not differ between CAT overexpressing cells and control U251 cells $(18.0 \pm 5.7 \mathrm{~h}$ and $21.5 \pm 4.1 \mathrm{~h}$, respectively; $p=0.68$ ) (Figure $3 \mathrm{~A}$ ). However, CAT overexpression markedly promoted colony formation in the anchorage-independent soft agar condition. In fact, colonies were present only in CAT-overexpressing cell cultures (209 \pm 23 ) (Figure 3B), supporting the notion that CAT can facilitate anchorage-independent growth. Treatment with 3-AT caused a 70\% reduction in the number of colonies (63 \pm 21 ) (Figure 3B), suggesting that the decrease in intracellular ROS levels caused by CAT overexpression is tightly associated with the increase in soft agar colonies. To assess the clinical relevance 
of this finding, we investigated the effect of CAT inhibition on the proliferation of GSCs freshly isolated from human GBM samples. As shown in Figure 3C, treatment with 3-AT significantly inhibited cell proliferation in all patient-derived GSC lines tested. To determine if CAT expression influences host survival, CAT-overexpressing or control U251 cells were implanted orthotopically into the brains of nude mice. Median survival was significantly shorter in mice bearing CAT-overexpressing tumor cells ( 33 days versus 48 days in mice bearing control tumor cells [ $p=0.0027]$ ) (Figure 3D). Notably, mice bearing CAT cells developed invasive tumors characterized by multifocal lesions throughout the brain parenchyma. In comparison, brains with vector-U251 tumors displayed only single lesions (Figure 3E). Overall, these results suggest the pivotal role of CAT in promoting glioma tumorigenicity and anchorage-independent growth, a hallmark of the aggressive GBM phenotype.

A
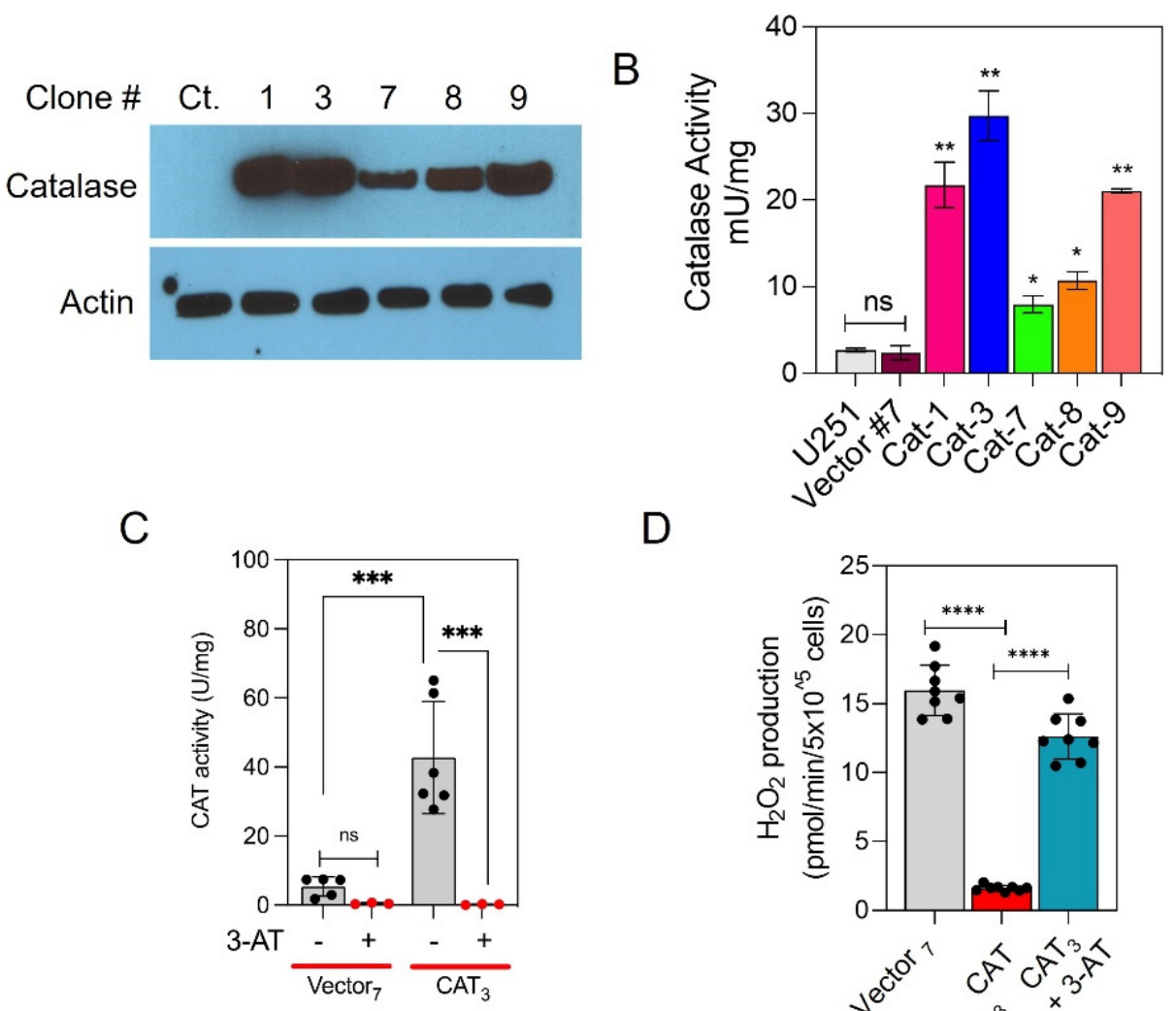

D

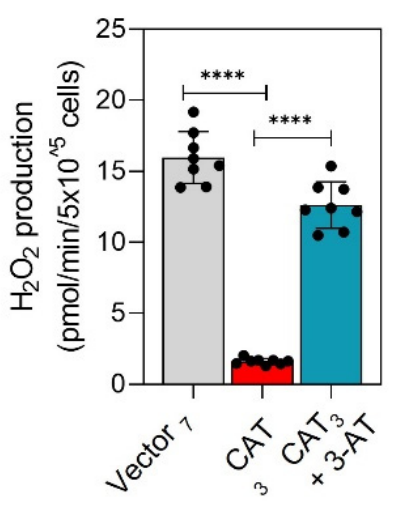

Figure 2. CAT expression and activity in stably transfected glioma cells. U251 cells were transfected with a CATexpressing (pCMV6-CAT--Myc-DDK) or control vector (pCMV6-Myc-DDK) construct and treated with G418 to produce stably transfected clones. (A) Representative Western blots depicting CAT protein expression in lysates of select clones. Actin was used as a loading control. (B) Quantitative analysis of mean CAT activity in the same clones. (C) Quantitative analysis of mean CAT activity in control or CAT-overexpressing U251 cells treated without or with the CAT inhibitor 3-amino-1,2,4-triazole (3-AT; $25 \mathrm{mM}$ for $24 \mathrm{~h}$ ) in select clones. (D) Bar graph showing the rate of $\mathrm{H}_{2} \mathrm{O}_{2}$ production as pmoles $/ \mathrm{min} / 10^{5}$ cells determined using the fluorescent probe AmplexRed. Graphs represent mean \pm SEM from duplicate determinations from three independent experiments. ${ }^{*} p<0.05,{ }^{* *} p<0.01,{ }^{* * *} p<0.001,{ }^{* * * *} p<0.0001$ calculated by Student's $t$-test.

\subsection{CAT Promotes Resistance to TMZ and Radiation}

Because the standard of care treatment for GBM involves TMZ as a chemotherapy agent, we used the clonogenic assay to investigate the in vitro long-term survival of glioma cells after TMZ treatment. TMZ had a clear dose-dependent cytotoxic effect on control U251 cells (Figure 4A); these doses were comparable in efficacy to TMZ's known cytotoxicity [29]. However, the cytotoxic effect of TMZ at any dose was mostly abolished in 
CAT-overexpressing U251 cells (cell survival rate with $250 \mu \mathrm{M} \mathrm{TMZ}, 93 \%$ and $10 \%$ for CAT-overexpressing and control cells, respectively) (Figure 4A). To evaluate the effect of TMZ on cell proliferation, we used flow cytometry to measure cell cycle progression in CAT-overexpressing and control cells treated with $300 \mu \mathrm{M} \mathrm{TMZ}$ for $48 \mathrm{~h}$. TMZ treatment led to $S$ phase accumulation that reached $72.7 \%(p<0.0001)$ at the expense of $G_{1}$ accumulation $(16.6 \%)$ in control cells but did not affect cell cycle distribution in CAT-overexpressing cells (Figure 4B). We also examined the induction of apoptosis using annexin $\mathrm{V} /$ propidium iodide (PI) staining and flow cytometry. Treatment with $300 \mu \mathrm{M} \mathrm{TMZ}$ for $48 \mathrm{~h}$ caused a $30 \%$ increase in the number of annexin V/PI-positive control cells but did not affect the number of annexin V/PI-positive CAT-overexpressing cells (Figure 4C). Interestingly, CAT-overexpressing cells were also resistant to treatment with staurosporine $(10 \mu \mathrm{M})$ (Figure 4C), a well-known inducer of apoptosis [39], suggesting that CAT-overexpressing glioma cells are resistant not only to TMZ but to apoptotic stimuli in general.

A

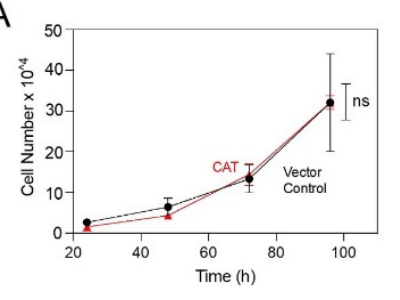

B

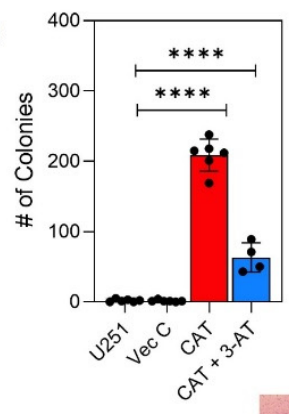

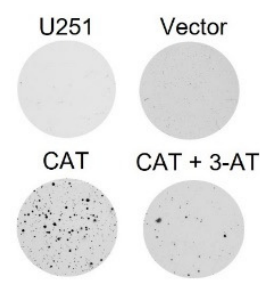

Vector
E

D

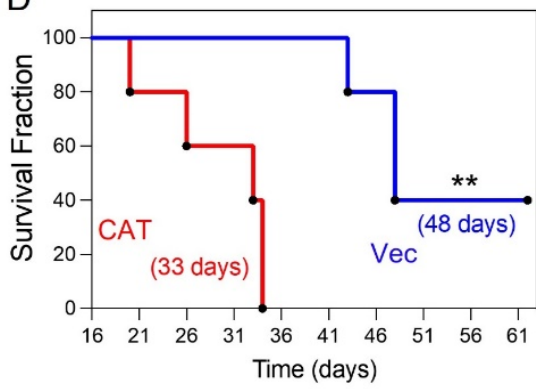

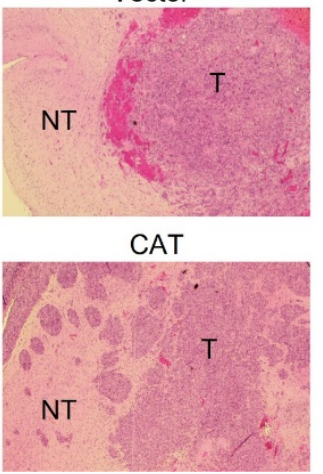

C
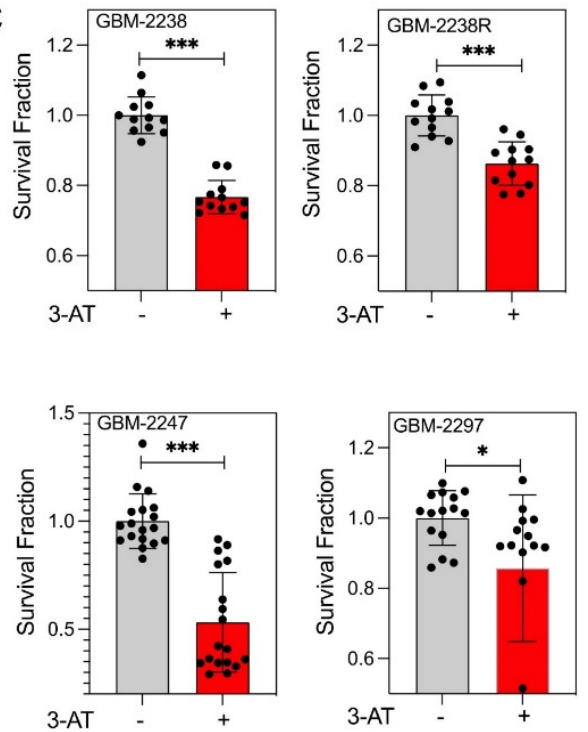

Figure 3. (A) Quantitative analysis of cell proliferation over time in adherent cultures of control and CAT-overexpressing U251 cells. (B) Quantitative analysis and representative images of anchorage-independent colony formation assays in control and CAT-overexpressing U251 cells cultured in the absence or presence of 3-AT (25 mM). (C) Quantitative analysis of proliferation in GSCs isolated from GBM patient biopsy samples and cultured in the presence or absence of 3-AT ( $25 \mathrm{nM})$. Data were pooled from three independent experiments. ${ }^{*} p<0.05$, ${ }^{* *} p<0.01,{ }^{* * *} p<0.001$, ${ }^{* * * *} p<0.0001$, ANOVA. (D) Kaplan-Meier survival curves of overall survival in nude mice harboring orthotopic brain tumors generated by inoculation with control $(n=5)$ or CAT-overexpressing $(n=5)$ U251 cells (Log-rank test $p=0.0027$; Wilcoxon test $p=0.0043$ ). (E) Representative images of tumors resulting from intracranial implantation of vector-control and CAT-overexpressing cells and stained for Hematoxylin and Eosin. Vec, vector; T, tumor; NT, normal tissue.

There is unequivocal pre-clinical and clinical evidence that ROS influence the genotoxic stress caused by ionizing radiation [40]. Given the important role of ROS production in mediating glioma cell sensitivity to radiation, we next examined the effect of radiation on clonogenic survival in the context of CAT overexpression. Treatment with radiation $(2,4,6$, or $8 \mathrm{~Gy})$ dose-dependently decreased the survival fraction in control cells, but the effect at 4,6 , and 8 Gy was markedly diminished in CAT-overexpressing cells $(p<0.0001)$ (Figure 4D). Pretreatment of CAT-overexpressing cells with 3-AT reduced the clonogenic survival after treatment with radiation $(p<0.0001)$ (Figure $4 \mathrm{D})$, further suggesting that CAT may protect glioma cells against radiation-induced toxicity. 

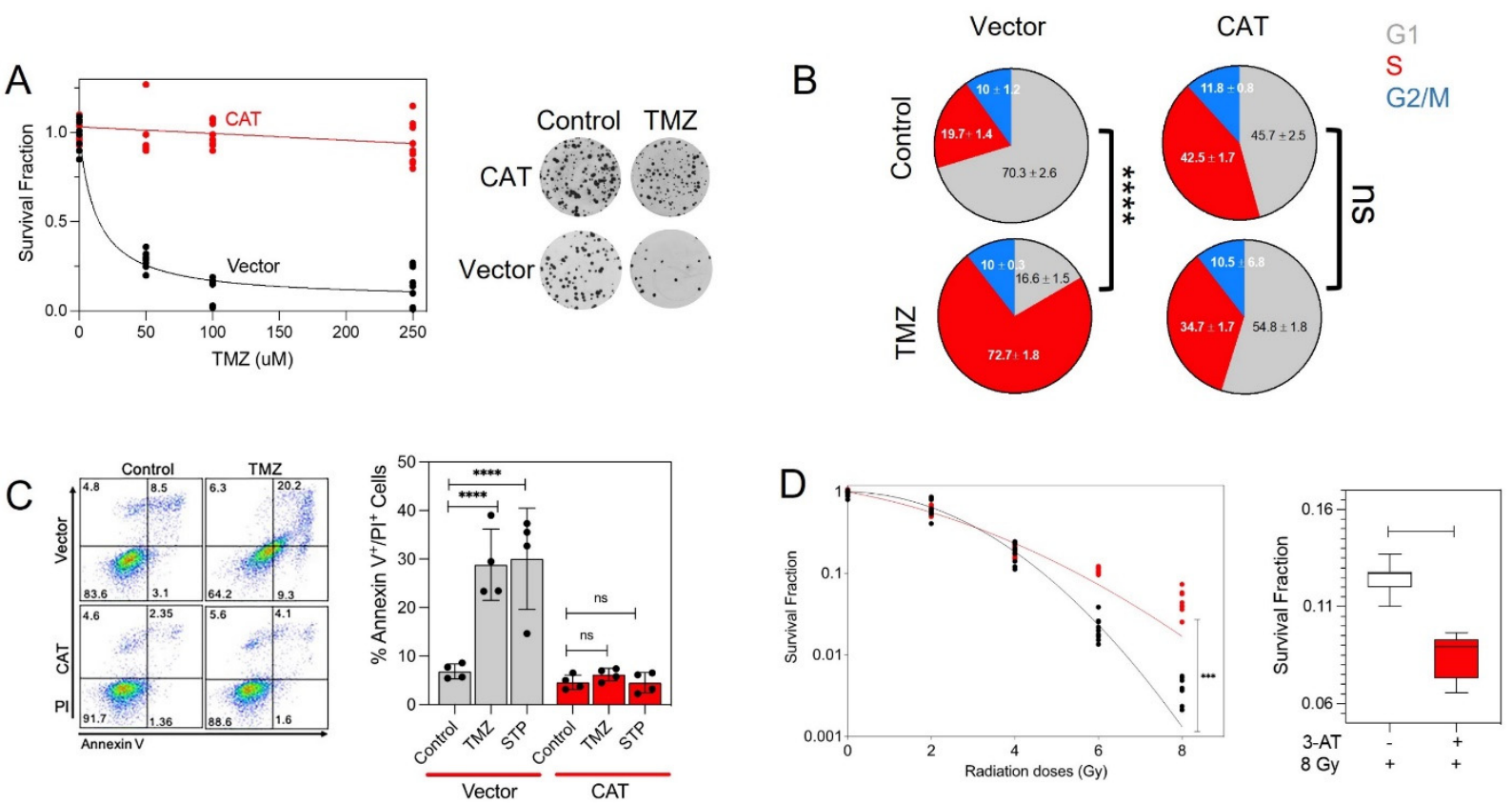

Figure 4. Effect of CAT overexpression on TMZ and radiation resistance in glioma cells. (A) Quantitative analysis and representative images of clonogenic survival assays with control and CAT-overexpressing U251 cells treated with various concentrations of TMZ. (B) Cell cycle distribution of cells treated with $300 \mu \mathrm{M}$ TMZ. Numbers indicate the percentage of cells in each phase of the cell cycle, as indicated. Graphs represent mean \pm SEM from duplicate determinations from three independent experiments. ${ }^{* * *} p<0.001,{ }^{* * * *} p<0.0001$ calculated by Student's $t$-test. (C) Determination of apoptotic cells in control and CAT-overexpressing U251 cells after treatment with $250 \mu \mathrm{M}$ TMZ or $10 \mu \mathrm{M}$ staurosporine (STP), a positive control for apoptosis. Representative flow cytometry plots obtained in cells treated with DMSO (control) or TMZ and stained for propidium iodide (PI) and annexin V (left); quantitative analysis of flow cytometry results (right). Columns represent the average from triplicate determinations of the percentage of apoptotic cells. (D) Quantitative analysis of clonogenic survival assays with control and CAT-overexpressing cells exposed to different radiation doses (left); survival fraction of CAT-overexpressing cells exposed to 8 Gy after pretreatment with 3-AT (25 mM) (right).

\subsection{CAT Promotes Neurosphere Formation}

Because we previously demonstrated that GSCs display higher CAT expression than non-tumor brain cells [21], we investigated whether CAT-overexpressing U251 cell cultures are enriched in GSCs when cultured in a neurobasal medium supplemented with epidermal growth factor (EGF) and basic fibroblast growth factor (bFGF). CAT-overexpressing cells formed neurospheres ranging from 0.1 to $1.0 \mathrm{~mm}$ in diameter over the course of 15 days. In contrast, control cells failed to form neurospheres and attached to the culture dish (Figure 5A). Furthermore, when plated in an in vitro limiting dilution assay, CAToverexpressing cells formed neurospheres, but control cells did not (Figure 5B). Treatment with 3-AT significantly reduced the frequency of GSCs in CAT-overexpressing cells (1 in 1.3 cells under control conditions versus 1 in 4.6 cells and 1 in 33.5 in cells treated with $5 \mathrm{mM}$ and $25 \mathrm{mM} 3-\mathrm{AT}$, respectively) (Figure 5B). These results suggest a critical role for CAT in mediating glioma neurosphere formation. 

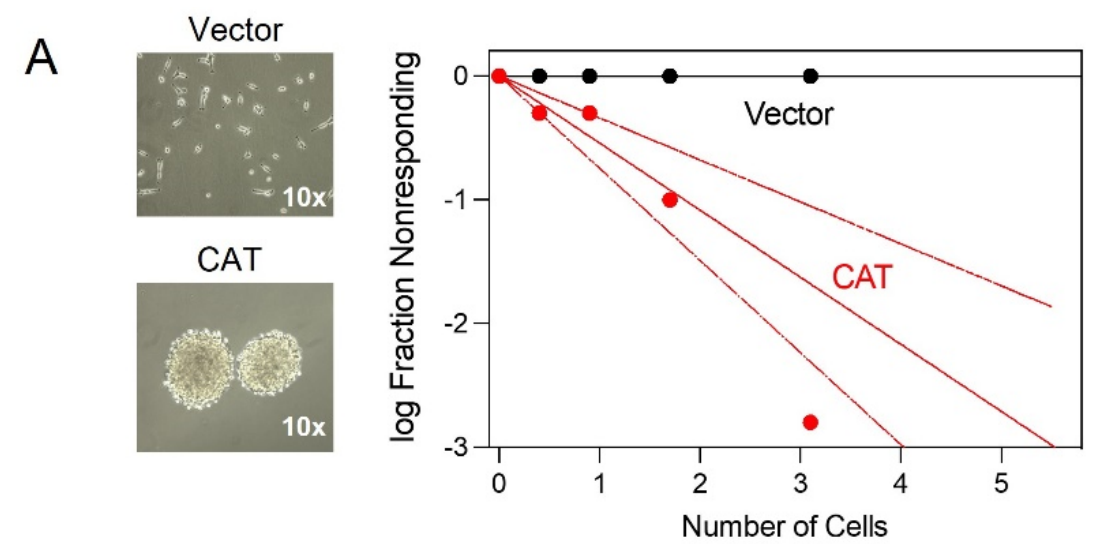

B
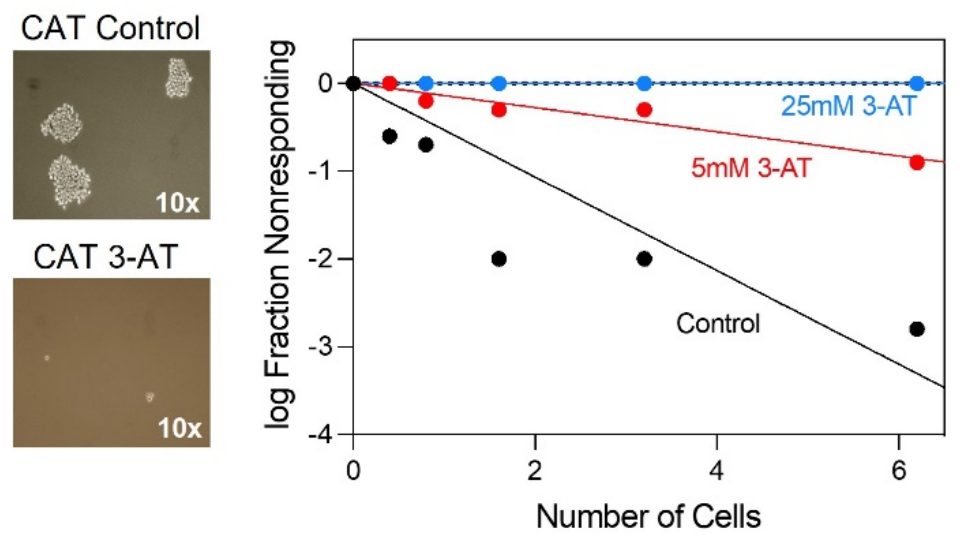

Figure 5. Effect of CAT overexpression on neurosphere formation. In vitro limiting dilution assays of (A) vector and CAT expressing cells; (B) CAT expressing cells in the presence or absence of 3-AT. Results represent the average from two independent experiments.

\section{Discussion}

Multiple mechanisms have been described to explain therapy resistance in gliomas, including drug inactivation, drug efflux, DNA damage repair, cell death inhibition, tumor hypoxia, and increased expression of antioxidant enzymes [41,42]. We previously demonstrated that TMZ-resistance in glioma cells is due to more efficient mitochondrial coupling and reduced ROS production. Specifically, under conditions of oxidative stress, TMZ-resistant glioma cells generate substantially less ROS and more antioxidant enzymes than TMZ-sensitive glioma cells [30]. Our previous studies also revealed increased expression of $\mathrm{CAT}$, superoxide dismutase $2\left(\mathrm{SOD}_{2}\right)$, and $\mathrm{BMI} 1$, a protein related to stemness and therapy resistance, in TMZ-resistant glioma cells [21]. In this study, we further assessed the role of CAT upregulation in glioma cell resistance to therapy and demonstrated that chemo- and radioresistance relies upon the regulation of hydrogen peroxide due, at least in part, to altered expression of CAT.

We found that human glioma cells stably overexpressing CAT express lower levels of intracellular $\mathrm{H}_{2} \mathrm{O}_{2}$ than control cells and are resistant to TMZ and radiation. Interestingly, we did not observe differences in the rate of proliferation of CAT and control cells in adherent culture conditions. However, CAT overexpression is associated with a significant increase in anchorage-independent proliferation, a hallmark of the aggressive cancer phenotype, and enhanced capacity for self-renewal. These effects were abrogated by treatment with 3-AT. Similar differences between adherent cell growth and anchorageindependent growth were previously observed in T98G [43], U87 and LN229 [44], and A172 [45] glioblastoma cells.

In agreement with our results, Smith et al. demonstrated that CAT activity is constitutively elevated in 36B10 rat glioma cells compared with normal astrocytes and has an important role in the resistance to oxidative stress and ionizing radiation [26]. Nanjaiah 
et al. also reported that activation of N-methyl-D-aspartate receptor (NMDAR) attenuated the intracellular ROS production and significantly enhanced the cell viability in LN18 and U251MG glioblastoma cells by increasing CAT activity. These results suggest that enhanced CAT activity contributes to glioma cell survival under exogenous oxidative stress [46].

Significant overexpression of CAT has been observed in a radioresistant variant clone (RRC) of U251 glioma cells. RRC showed an activation of up to 5-fold of antioxidant enzymes, such as SOD, CAT, glutathione peroxidase (GPX), and glutathione reductase (GR). Compared with parental U251 cells, RRC cells increase the activity of major antioxidant enzymes at times soon after radiation, suggesting a rapid scavenge of ROS to minimize the deleterious effects of radiation [23]. As Lee et al. demonstrated, exposure to radiation upregulated CAT and other oxidant enzymes and increased radio and chemoresistance. Our study demonstrated that overexpression of CAT is, at least in part, responsible for the resistant phenotype.

Significant overexpression of CAT has also been observed in human melanoma biopsy samples [18], colon cancer tissue [19], and gastric carcinoma cells [20]. In contrast, it was reported that the expression of antioxidant enzymes decreases during the progression from the normal pancreas to chronic pancreatitis to pancreatic cancer [16]. Similarly, CAT downregulation has been reported during skin cancer progression [17]. Interestingly, CAT overexpression in MCF-7 human breast cancer cells impaired cell proliferation and sensitized the cells to paclitaxel, etoposide, and arsenic trioxide [47]. The discrepancy between results may be due to cell type-specific responses or variations in experimental conditions. Even though our results clearly support a role for CAT in the mechanism of chemo- and radioresistance, we cannot exclude the possibility that the switch to a therapyresistant phenotype could be the result of a coordinate effect of multiple antioxidant enzymes. For example, it was recently reported that $\mathrm{SOD}_{2}$ expression critically regulates tumorigenesis and the acquisition of TMZ resistance in GBM [48]. Additionally, it has been recently suggested that ROS regulates nuclear epigenetic modifications to promote cell survival and stemness [49-52]. Even though our results clearly support a role for CAT in chemo- and radioresistance, additional research is required to fully understand the underlying mechanism.

Here we also found that a shorter survival time was associated with orthotopic xenograft mice bearing glioma cell overexpression of CAT. Notably, CAT tumors are invasive and multifocal, while vector cells develop single lesions. Multifocal GBMs are rare and usually associated with worse outcomes compared with single lesion GBMs [53,54], supporting an important role of CAT in the development of more aggressive tumors.

\section{Conclusions}

Overall, this study provides strong evidence suggesting that overexpression of CAT in glioma cells leads to increased resistance to TMZ and radiation, suggesting an essential role of $\mathrm{H}_{2} \mathrm{O}_{2}$ in the molecular mechanism by which these treatments lead to tumor cytotoxicity. As a crucial factor in the acquisition of TMZ and radiation resistance, pharmacological inhibition of CAT activity is a promising strategy for the treatment of malignant gliomas, including highly aggressive GBM tumors.

Supplementary Materials: Gene expression data is available online at http:/ / gliovis.bioinfo.cnio.es / (accessed on 8 September 2021) and https:/ / www.mdpi.com/article/10.3390/antiox10121988/s1, Table S1, Catalase mRNA expression.

Author Contributions: Conceptualization, C.E.G. and C.R.O.; investigation, C.E.G., C.R.O., S.F. and M.Y.A.; resources, C.E.G.; C.R.O., K.L.C., J.D.G., K.A.J. and V.M.; writing, C.E.G., C.R.O. and S.F. All authors have read and agreed to the published version of the manuscript.

Funding: This work was supported by grant IRG-15-176-41 from the American Cancer Society, administered through the Holden Comprehensive Cancer Center at The University of Iowa, and by The National Institute of Health grants R01CA160821 and 5R21NS100054. 
Institutional Review Board Statement: The study was conducted according to the guidelines of the Declaration of Helsinki and approved by the Institutional Review Board of the University of Iowa (IRB 201103721).

Informed Consent Statement: Informed consent was obtained from all subjects involved in the study.

Data Availability Statement: The data is contained within the article or Supplementary Materials.

Acknowledgments: The authors are grateful to members of the Tissue Procurement Core at the University of Iowa for their assistance in collecting patient specimens. We wish to acknowledge Erin Thacker for manuscript editing.

Conflicts of Interest: M.V. is an Advisor for Astex Pharmaceuticals and Forma Therapeutics, and a Consultant for Rising Tide Foundation. The funders had no role in the design of the study; in the collection, analyses, or interpretation of data; in the writing of the manuscript, or in the decision to publish the results.

\section{References}

1. Poon, M.T.; Sudlow, C.L.; Figueroa, J.D.; Brennan, P.M. Longer-term ( $\geq 2$ years) survival in patients with glioblastoma in population-based studies pre- and post-2005: A systematic review and meta-analysis. Sci. Rep. 2020, 10, 11622. [CrossRef]

2. Hegi, M.E.; Diserens, A.C.; Gorlia, T.; Hamou, M.F.; de Tribolet, N.; Weller, M.; Kros, J.M.; Hainfellner, J.A.; Mason, W.; Mariani, L.; et al. MGMT gene silencing and benefit from temozolomide in glioblastoma. N. Engl. J. Med. 2005, 352, 997-1003. [CrossRef]

3. Hegi, M.E.; Liu, L.; Herman, J.G.; Stupp, R.; Wick, W.; Weller, M.; Mehta, M.P.; Gilbert, M.R. Correlation of O6-methylguanine methyltransferase (MGMT) promoter methylation with clinical outcomes in glioblastoma and clinical strategies to modulate MGMT activity. J. Clin. Oncol. 2008, 26, 4189-4199. [CrossRef] [PubMed]

4. Stupp, R.; Mason, W.P.; van den Bent, M.J.; Weller, M.; Fisher, B.; Taphoorn, M.J.; Belanger, K.; Brandes, A.A.; Marosi, C.; Bogdahn, U.; et al. Radiotherapy plus concomitant and adjuvant temozolomide for glioblastoma. N. Engl. J. Med. 2005, 352, 987-996. [CrossRef]

5. Stupp, R.; van den Bent, M.J.; Hegi, M.E. Optimal role of temozolomide in the treatment of malignant gliomas. Curr. Neurol. Neurosci. Rep. 2005, 5, 198-206. [CrossRef] [PubMed]

6. Jeggo, P.; Lavin, M.F. Cellular radiosensitivity: How much better do we understand it? Int. J. Radiat. Biol. 2009, 85, 1061-1081. [CrossRef] [PubMed]

7. Prager, B.C.; Bhargava, S.; Mahadev, V.; Hubert, C.G.; Rich, J.N. Glioblastoma Stem Cells: Driving Resilience through Chaos. Trends Cancer 2020, 6, 223-235. [CrossRef] [PubMed]

8. Sun, J.; Chen, Y.; Li, M.; Ge, Z. Role of antioxidant enzymes on ionizing radiation resistance. Free Radic. Biol. Med. 1998, 24, 586-593. [CrossRef]

9. Fisher, C.J.; Goswami, P.C. Mitochondria-targeted antioxidant enzyme activity regulates radioresistance in human pancreatic cancer cells. Cancer Biol. Ther. 2008, 7, 1271-1279. [CrossRef] [PubMed]

10. Kumari, S.; Badana, A.K.; Malla, R. Reactive Oxygen Species: A Key Constituent in Cancer Survival. Biomark. Insights 2018, 13, 1177271918755391. [CrossRef] [PubMed]

11. Perillo, B.; Di Donato, M.; Pezone, A.; Di Zazzo, E.; Giovannelli, P.; Galasso, G.; Castoria, G.; Migliaccio, A. ROS in cancer therapy: The bright side of the moon. Exp. Mol. Med. 2020, 52, 192-203. [CrossRef]

12. Cross, C.E.; Halliwell, B.; Borish, E.T.; Pryor, W.A.; Ames, B.N.; Saul, R.L.; McCord, J.M.; Harman, D. Oxygen radicals and human disease. Ann. Intern. Med. 1987, 107, 526-545. [CrossRef]

13. Redza-Dutordoir, M.; Averill-Bates, D.A. Activation of apoptosis signalling pathways by reactive oxygen species. Biochim. Biophys. Acta 2016, 1863, 2977-2992. [CrossRef]

14. Schieber, M.; Chandel, N.S. ROS function in redox signaling and oxidative stress. Curr. Biol. 2014, 24, R453-462. [CrossRef]

15. Menegon, S.; Columbano, A.; Giordano, S. The Dual Roles of NRF2 in Cancer. Trends Mol. Med. 2016, 22, 578-593. [CrossRef]

16. Cullen, J.J.; Mitros, F.A.; Oberley, L.W. Expression of antioxidant enzymes in diseases of the human pancreas: Another link between chronic pancreatitis and pancreatic cancer. Pancreas 2003, 26, 23-27. [CrossRef]

17. Kwei, K.A.; Finch, J.S.; Thompson, E.J.; Bowden, G.T. Transcriptional repression of catalase in mouse skin tumor progression. Neoplasia 2004, 6, 440-448. [CrossRef]

18. Sander, C.S.; Hamm, F.; Elsner, P.; Thiele, J.J. Oxidative stress in malignant melanoma and non-melanoma skin cancer. Br. J. Dermatol. 2003, 148, 913-922. [CrossRef]

19. Rainis, T.; Maor, I.; Lanir, A.; Shnizer, S.; Lavy, A. Enhanced oxidative stress and leucocyte activation in neoplastic tissues of the colon. Dig. Dis. Sci. 2007, 52, 526-530. [CrossRef]

20. Hwang, T.S.; Choi, H.K.; Han, H.S. Differential expression of manganese superoxide dismutase, copper/zinc superoxide dismutase, and catalase in gastric adenocarcinoma and normal gastric mucosa. Eur. J. Surg. Oncol. 2007, 33, 474-479. [CrossRef]

21. Oliva, C.R.; Markert, T.; Gillespie, G.Y.; Griguer, C.E. Nuclear-encoded cytochrome c oxidase subunit 4 regulates BMI1 expression and determines proliferative capacity of high-grade gliomas. Oncotarget 2015, 6, 4330-4344. [CrossRef] 
22. Zhong, W.; Yan, T.; Lim, R.; Oberley, L.W. Expression of superoxide dismutases, catalase, and glutathione peroxidase in glioma cells. Free Radic. Biol. Med. 1999, 27, 1334-1345. [CrossRef]

23. Lee, H.C.; Kim, D.W.; Jung, K.Y.; Park, I.C.; Park, M.J.; Kim, M.S.; Woo, S.H.; Rhee, C.H.; Yoo, H.; Lee, S.H.; et al. Increased expression of antioxidant enzymes in radioresistant variant from U251 human glioblastoma cell line. Int. J. Mol. Med. 2004, 13, 883-887. [CrossRef]

24. Glorieux, C.; Sandoval, J.M.; Dejeans, N.; Nonckreman, S.; Bahloula, K.; Poirel, H.A.; Calderon, P.B. Evaluation of Potential Mechanisms Controlling the Catalase Expression in Breast Cancer Cells. Oxid. Med. Cell. Longev. 2018, 2018, 5351967. [CrossRef]

25. Zhou, D.; Shao, L.; Spitz, D.R. Reactive oxygen species in normal and tumor stem cells. Adv. Cancer Res. 2014, $122,1-67$.

26. Smith, P.S.; Zhao, W.; Spitz, D.R.; Robbins, M.E. Inhibiting catalase activity sensitizes 36 B10 rat glioma cells to oxidative stress. Free Radic. Biol. Med. 2007, 42, 787-797. [CrossRef]

27. Zhong, W.; Oberley, L.W.; Oberley, T.D.; St Clair, D.K. Suppression of the malignant phenotype of human glioma cells by overexpression of manganese superoxide dismutase. Oncogene 1997, 14, 481-490. [CrossRef]

28. Weydert, C.J.; Cullen, J.J. Measurement of superoxide dismutase, catalase and glutathione peroxidase in cultured cells and tissue. Nat. Protoc. 2010, 5, 51-66. [CrossRef]

29. Oliva, C.R.; Nozell, S.E.; Diers, A.; McClugage, S.G.; Sarkaria, J.N., 3rd; Markert, J.M.; Darley-Usmar, V.M.; Bailey, S.M.; Gillespie, G.Y.; Landar, A.; et al. Acquisition of temozolomide chemoresistance in gliomas leads to remodeling of mitochondrial electron transport chain. J. Biol. Chem. 2010, 285, 39759-39767. [CrossRef]

30. Oliva, C.R.; Moellering, D.R.; Gillespie, G.Y.; Griguer, C.E. Acquisition of chemoresistance in gliomas is associated with increased mitochondrial coupling and decreased ROS production. PLOS ONE 2011, 6, e24665. [CrossRef]

31. Griguer, C.E.; Oliva, C.R.; Gobin, E.; Marcorelles, P.; Benos, D.J.; Lancaster, J.R.; Jr Gillespie, G.Y. CD133 is a marker of bioenergetic stress in human glioma. PLoS ONE 2008, 3, e3655. [CrossRef]

32. Hollinshead, K.E.R.; Parker, S.J.; Eapen, V.V.; Encarnacion-Rosado, J.; Sohn, A.; Oncu, T.; Cammer, M.; Mancias, J.D.; Kimmelman, A.C. Respiratory Supercomplexes Promote Mitochondrial Efficiency and Growth in Severely Hypoxic Pancreatic Cancer. Cell Rep. 2020, 33, 108231. [CrossRef]

33. Griguer, C.E.; Oliva, C.R.; Kelley, E.E.; Giles, G.I.; Lancaster, J.R.; Jr Gillespie, G.Y. Xanthine oxidase-dependent regulation of hypoxia-inducible factor in cancer cells. Cancer Res. 2006, 66, 2257-2263. [CrossRef]

34. Oliva, C.R.; Zhang, W.; Langford, C.; Suto, M.J.; Griguer, C.E. Repositioning chlorpromazine for treating chemoresistant glioma through the inhibition of cytochrome c oxidase bearing the COX4-1 regulatory subunit. Oncotarget 2017, 8, 37568-37583. [CrossRef]

35. Franken, N.A.; Rodermond, H.M.; Stap, J.; Haveman, J.; van Bree, C. Clonogenic assay of cells in vitro. Nat. Protoc. 2006, 1, 2315-2319. [CrossRef]

36. Oliva, C.R.; Markert, T.; Ross, L.J.; White, E.L.; Rasmussen, L.; Zhang, W.; Everts, M.; Moellering, D.R.; Bailey, S.M.; Suto, M.J.; et al. Identification of Small Molecule Inhibitors of Human Cytochrome c Oxidase That Target Chemoresistant Glioma Cells. J. Biol. Chem. 2016, 291, 24188-24199. [CrossRef]

37. Bowman, R.L.; Wang, Q.; Carro, A.; Verhaak, R.G.; Squatrito, M. GlioVis data portal for visualization and analysis of brain tumor expression datasets. Neuro-Oncology 2017, 19, 139-141. [CrossRef]

38. Sheikh, F.G.; Pahan, K.; Khan, M.; Barbosa, E.; Singh, I. Abnormality in catalase import into peroxisomes leads to severe neurological disorder. Proc. Natl. Acad. Sci. USA 1998, 95, 2961-2966. [CrossRef]

39. Belmokhtar, C.A.; Hillion, J.; Segal-Bendirdjian, E. Staurosporine induces apoptosis through both caspase-dependent and caspase-independent mechanisms. Oncogene 2001, 20, 3354-3362. [CrossRef]

40. Srinivas, U.S.; Tan, B.W.Q.; Vellayappan, B.A.; Jeyasekharan, A.D. ROS and the DNA damage response in cancer. Redox Biol. 2019, 25, 101084. [CrossRef]

41. Housman, G.; Byler, S.; Heerboth, S.; Lapinska, K.; Longacre, M.; Snyder, N.; Sarkar, S. Drug resistance in cancer: An overview. Cancers 2014, 6, 1769-1792. [CrossRef]

42. Chien, C.H.; Hsueh, W.T.; Chuang, J.Y.; Chang, K.Y. Dissecting the mechanism of temozolomide resistance and its association with the regulatory roles of intracellular reactive oxygen species in glioblastoma. J. Biomed. Sci. 2021, 28, 18. [CrossRef]

43. Haga, Y.; Yanagisawa, K.; Ohto-Ozaki, H.; Tominaga, S.; Masuzawa, T.; Iwahana, H. The effect of ST2 gene product on anchorageindependent growth of a glioblastoma cell line, T98G. Eur. J. Biochem. 2003, 270, 163-170. [CrossRef]

44. Choi, S.H.; Kim, J.K.; Jeon, H.Y.; Eun, K.; Kim, H. OCT4B Isoform Promotes Anchorage-Independent Growth of Glioblastoma Cells. Mol. Cells 2019, 42, 135-142.

45. Kunapuli, P.; Chitta, K.S.; Cowell, J.K. Suppression of the cell proliferation and invasion phenotypes in glioma cells by the LGI1 gene. Oncogene 2003, 22, 3985-3991. [CrossRef]

46. Nanjaiah, N.D.; Ramaswamy, P.; Goswami, K.; Fathima, K.H.; Borkotokey, M. Survival of glioblastoma cells in response to endogenous and exogenous oxidative challenges: Possible implication of NMDA receptor-mediated regulation of redox homeostasis. Cell Biol. Int. 2019, 43, 1443-1452. [CrossRef]

47. Glorieux, C.; Dejeans, N.; Sid, B.; Beck, R.; Calderon, P.B.; Verrax, J. Catalase overexpression in mammary cancer cells leads to a less aggressive phenotype and an altered response to chemotherapy. Biochem. Pharmacol. 2011, 82, 1384-1390. [CrossRef] 
48. Chien, C.H.; Chuang, J.Y.; Yang, S.T.; Yang, W.B.; Chen, P.Y.; Hsu, T.I.; Huang, C.Y.; Lo, W.L.; Yang, K.Y.; Liu, M.S.; et al. Enrichment of superoxide dismutase 2 in glioblastoma confers to acquisition of temozolomide resistance that is associated with tumor-initiating cell subsets. J. Biomed. Sci. 2019, 26, 77. [CrossRef]

49. Toh, T.B.; Lim, J.J.; Chow, E.K. Epigenetics in cancer stem cells. Mol. Cancer 2017, 16, 29. [CrossRef]

50. Shrishrimal, S.; Kosmacek, E.A.; Oberley-Deegan, R.E. Reactive Oxygen Species Drive Epigenetic Changes in Radiation-Induced Fibrosis. Oxid. Med. Cell. Longev. 2019, 2019, 4278658. [CrossRef]

51. Cerda, S.; Weitzman, S.A. Influence of oxygen radical injury on DNA methylation. Mutat. Res. 1997, 386, 141-152. [CrossRef]

52. Franco, R.; Schoneveld, O.; Georgakilas, A.G.; Panayiotidis, M.I. Oxidative stress, DNA methylation and carcinogenesis. Cancer Lett. 2008, 266, 6-11. [CrossRef]

53. Abou-El-Ardat, K.; Seifert, M.; Becker, K.; Eisenreich, S.; Lehmann, M.; Hackmann, K.; Rump, A.; Meijer, G.; Carvalho, B.; Temme, A.; et al. Comprehensive molecular characterization of multifocal glioblastoma proves its monoclonal origin and reveals novel insights into clonal evolution and heterogeneity of glioblastomas. Neuro-Oncology 2017, 19, 546-557. [CrossRef]

54. Zhang, Z.X.; Chen, J.X.; Shi, B.Z.; Li, G.H.; Li, Y.; Xiang, Y.; Qin, X.; Yang, L.; Lv, S.Q. Multifocal glioblastoma-two case reports and literature review. Chin. Neurosurg. J. 2021, 7, 8. [CrossRef] 